\title{
The Robustness Of The Basic EOQ
}

\author{
Louie Ren, University of Houston - Victoria, USA
}

\begin{abstract}
The robustness of the basic Economic Ordering Quantity (EOQ) is studied for annual demand, set-up cost, and holding cost from various uniform and normal probability distributions. Instead of comparing $T C^{*}(\hat{Q})$ and $T C^{*}\left(Q^{*}\right)$ where $\hat{Q}$ is an estimate of $Q^{*}$, the $\widehat{T C}(\hat{Q})$ and $T C^{*}\left(Q^{*}\right)$ are compared where $\widehat{T C}(\hat{Q})$ is the total cost from realizations of annual demand, set-up cost, and holding cost. Simulation results show the robustness of the basic EOQ.
\end{abstract}

Keywords: Basic EOQ; Cost and Demand Distribution; Cost and Demand Realization; Sensitivity Analysis

\section{INTRODUCTION}

nder the assumptions of Basic Economic Ordering Quantity (EOQ) model (Stevenson, 2009), the EOQ, which minimizes the total annual inventory holding and set-up costs, is

$\mathrm{Q}^{*}=\sqrt{\frac{2 \mathrm{D}^{*} \mathrm{~S}^{*}}{\mathrm{H}^{*}}}$

where $\mathrm{D}^{*}, \mathrm{~S}^{*}$, and $\mathrm{H}^{*}$ are the true given annual demand, set-up cost per order, and annual holding cost per unit, respectively. The corresponding true minimized annual total cost, $\mathrm{TC}^{*}\left(\mathrm{Q}^{*}\right)$, is

$\mathrm{TC}^{*}\left(\mathrm{Q}^{*}\right)=\frac{\mathrm{Q}^{*}}{2} \mathrm{H}^{*}+\frac{\mathrm{D}^{*}}{\mathrm{Q}^{*}} \mathrm{~S}^{*}=\frac{\sqrt{2 \mathrm{D}^{*} \mathrm{~S}^{*} \mathrm{H}^{*}}}{2}+\frac{\sqrt{2 \mathrm{D}^{*} \mathrm{~S}^{*} \mathrm{H}^{*}}}{2}=\sqrt{2 \mathrm{D}^{*} \mathrm{~S}^{*} \mathrm{H}^{*}}$.

Since the annual total cost curve from equation (2) is very flat around $\mathrm{Q}^{*}$, it gives the flexibility for the ordering quantity without increasing much to the total cost.

For instance, given true annual demand $\mathrm{D}^{*}=9,600$ units, set-up cost $\mathrm{S}^{*}=\$ 75$ per order, and $\mathrm{H}^{*}=$ $(16 \%)(\$ 100)=\$ 16$ per unit per year. The EOQ from equation $(1), Q^{*}=\sqrt{\frac{2(9,600)(75)}{16}}=300$ units and the corresponding optimal annual total cost from equation (2) will be $\mathrm{TC}^{*}(300)=\frac{300}{2}(\$ 16)+\frac{9,600}{300}(\$ 75)=\$ 2,400+$ $\$ 2,400=\$ 4,800$.

However, due to some constraints (say, the full truckload constraint, etc.), the ordering quantity, $\widehat{Q}$, has to be 360 units, which is about $20 \%$ more than the optimal EOQ of 300 units being ordered. Accordingly, the annual total cost, $\mathrm{TC}^{*}(\widehat{\mathrm{Q}})$, corresponding to the true set-up cost $\mathrm{S}^{*}=\$ 75$ and true holding cost $\mathrm{H}^{*}=\$ 16$, is $=\frac{360}{2}(\$ 16)+$ $\frac{9,600}{360}(\$ 75)=\$ 2,840+\$ 2,000=\$ 4,880$. The ratio of proportional increase of the total annual cost is $\frac{\$ 4,880}{\$ 4,800}=1.0167$.

An analytical sensitivity analysis of the EOQ was studied by Low and Schwarz (1983). In the study, the annual demand, D, set-up cost, S, and holding cost, H, are assumed to be stationary but unknown quantities over the following ranges:

$\mathrm{D}_{\mathrm{L}} \leq \mathrm{D} \leq \mathrm{D}_{\mathrm{u}}$,

$\mathrm{S}_{\mathrm{L}} \leq \mathrm{S} \leq \mathrm{S}_{\mathrm{u}}$,

$\mathrm{H}_{\mathrm{L}} \leq \mathrm{H} \leq \mathrm{H}_{\mathrm{u}}$, 
where we assume that at least one of the pairs of upper and lower bounds are unequal. Then the optimal choice of $\widehat{Q}$ for the problem is

$\underset{\text { Minimize }}{\text { w.r.t. } \widehat{Q}}\left\{\begin{array}{c}\operatorname{Max} R(\widehat{Q}) \\ \text { w.r.t. }(\mathrm{D}, \mathrm{S}, \mathrm{H})\end{array}\right\}$
is $\widehat{\mathrm{Q}}=\sqrt{\frac{2 \sqrt{\mathrm{D}_{\mathrm{U}} \mathrm{S}_{\mathrm{U}} / \mathrm{H}_{\mathrm{U}}}}{\sqrt{\mathrm{D}_{\mathrm{L}} \mathrm{S}_{\mathrm{L}} / \mathrm{H}_{\mathrm{L}}}}}$. $\operatorname{cost} \mathrm{H}^{*}$, is

Accordingly, the annual total cost, $\mathrm{TC}^{*}(\widehat{\mathrm{Q}})$, corresponding to the true ordering cost $\mathrm{S}^{*}$, and true holding

$\mathrm{TC}^{*}(\widehat{\mathrm{Q}})=\frac{\widehat{\mathrm{Q}}}{2} \mathrm{H}^{*}+\frac{\mathrm{D}^{*}}{\widehat{\mathrm{Q}}} \mathrm{S}^{*}=\left(\frac{\widehat{\mathrm{Q}}}{\mathrm{Q}^{*}}\right) \frac{\mathrm{Q}^{*}}{2} \mathrm{H}^{*}+\left(\frac{\widehat{\mathrm{Q}}}{\mathrm{Q}^{*}}\right) \frac{\mathrm{D}^{*}}{\mathrm{Q}^{*}} \mathrm{~S}^{*}=\left(\sqrt{\mathrm{e}}+\sqrt{\frac{1}{\mathrm{e}}}\right) \frac{\mathrm{TC}\left(\mathrm{Q}^{*}\right)}{2}$,

where $\mathrm{e}=\frac{\widehat{\mathrm{Q}}}{\mathrm{Q}^{*}}$ and the ratio for the proportion increase in total annual cost is

$\mathrm{R}_{1}=\frac{\mathrm{TC}^{*}(\widehat{\mathrm{Q}})}{\mathrm{TC}^{*}\left(\mathrm{Q}^{*}\right)}=\left(\sqrt{\mathrm{e}}+\sqrt{\frac{1}{\mathrm{e}}}\right) / 2$.

From Equation (2), the ratio $\mathrm{R}_{1}$ can be rewritten as

$\mathrm{R}_{1}=\frac{\mathrm{TC}^{*}(\widehat{\mathrm{Q}})}{\mathrm{TC}^{*}\left(\mathrm{Q}^{*}\right)}=\frac{\frac{\widehat{\mathrm{Q}}_{\mathrm{Q}}}{2} \mathrm{H}^{*}+\frac{\mathrm{D}^{*}}{\widehat{\mathrm{Q}}} \mathrm{S}^{*}}{\sqrt{2 \mathrm{D}^{*} \mathrm{~S}^{*} \mathrm{H}^{*}}}=2^{-3 / 2} \sqrt{\frac{\mathrm{H}^{*}}{\mathrm{D}^{*} \mathrm{~S}^{*}}} \widehat{\mathrm{Q}}+2^{-1 / 2} \sqrt{\frac{\mathrm{D}^{*} \mathrm{~S}^{*}}{\mathrm{H}^{*}}} \widehat{\mathrm{Q}}^{-1}=2^{-3 / 2} \mathrm{y} \widehat{\mathrm{Q}}+2^{-1 / 2} \mathrm{y}^{-1} \widehat{\mathrm{Q}}^{-1}$,

where $y=\sqrt{\frac{\mathrm{H}^{*}}{\mathrm{D}^{*} \mathrm{~S}^{*}}}$. By fixing the $\widehat{\mathrm{Q}}$, we can find the maximum for an equation ay+by ${ }^{-1}$ in the interval $\left[\mathrm{y}_{\mathrm{L}}, \mathrm{y}_{\mathrm{u}}\right]$ where $y_{L}=\sqrt{\frac{H_{L}}{D_{U} S_{U}}}$, and $y_{u}=\sqrt{\frac{H_{U}}{D_{L} S_{L}}}$. The process is basically the same as what we did from the convex curve for the total annual cost, a sum of functions for $y$ and $\mathrm{y}^{-1}$. After finding the $\mathrm{y}^{*}$, which maximizes the equation ay+by ${ }^{-1}$ in the interval $\left[\mathrm{y}_{\mathrm{L}}, \mathrm{y}_{\mathrm{u}}\right]$, we can then find the optimal solution, $\widehat{\mathrm{Q}}^{*}$, from the equation $2^{-3 / 2} \mathrm{y}^{*} \widehat{\mathrm{Q}}+2^{-1 / 2} \mathrm{y}^{*-1} \widehat{\mathrm{Q}}^{-1}$ to be $\widehat{\mathrm{Q}}^{*}=$ $\sqrt{\frac{2 \sqrt{D_{U} S_{U} H_{L}}}{\sqrt{\bar{D}_{L} S_{L} / H_{U}}}}$. The process is also the same as what we did from the convex curve for the total annual cost for an equation with $\widehat{\mathrm{Q}}$ and $\widehat{\mathrm{Q}}^{-1}$ and setting the two summation terms to be equal.

\section{ANNUAL DEMAND, SET-UP COST, AND HOLDING COST ARE RANDOM VARIABLES}

In reality, the true values for $\mathrm{D}^{*}, \mathrm{~S}^{*}$, and $\mathrm{H}^{*}$ would not be known; therefore, it is unrealistic to calculate the $\mathrm{TC}^{*}(\widehat{\mathrm{Q}})=\frac{\widehat{\mathrm{Q}}}{2} \mathrm{H}^{*}+\frac{\mathrm{D}^{*}}{\widehat{Q}} \mathrm{~S}^{*}$ for comparison. Practitioners would have taken the realizations of $\widehat{\mathrm{D}}, \widehat{\mathrm{S}}$, and $\widehat{\mathrm{H}}$ as their true values and used them to figure out the annual total cost. $\widehat{T C}(\widehat{Q})=\frac{\widehat{Q}}{2} \widehat{H}+\frac{\widehat{D}}{\widehat{Q}} \widehat{S}$.

In this study, $\widehat{D}, \widehat{S}$, and $\widehat{H}$ are assumed to be random variables with means of $\mathrm{D}^{*}, \mathrm{~S}^{*}$, and $\mathrm{H}^{*}$, respectively. The realization of $\widehat{\mathrm{D}}, \widehat{\mathrm{S}}$, and $\widehat{\mathrm{H}}$ is used to find the realization of EOQ, $\widehat{\mathrm{Q}}$, in equation (1) and its realization annual total cost, $\widehat{\mathrm{TC}}(\widehat{\mathrm{Q}})$, with

$\widehat{\mathrm{TC}}(\widehat{\mathrm{Q}})=\frac{\widehat{Q}}{2} \widehat{\mathrm{H}}+\frac{\widehat{\mathrm{D}}}{\mathrm{Q}} \widehat{\mathrm{S}}=\frac{\sqrt{2 \widehat{\mathrm{D}} \widehat{\mathrm{S}} \mathrm{H}}}{2}+\frac{\sqrt{2 \widehat{\mathrm{D}} \widehat{\mathrm{S}} \mathrm{H}}}{2}=\sqrt{2 \widehat{\mathrm{D}} \widehat{\mathrm{S}} \widehat{H}}$.

to be

From it, we have the ratio for the proportion increase in realization total annual cost to the true annual cost 
$\mathrm{R}_{2}=\frac{\widehat{\mathrm{TC}}(\widehat{\mathrm{Q}})}{\mathrm{TC}^{*}\left(\mathrm{Q}^{*}\right)}=\frac{\sqrt{\widehat{\mathrm{D}} \widehat{\mathrm{S}}}}{\sqrt{\mathrm{D}^{*} \mathrm{~S}^{*} \mathrm{H}^{*}}}$

By Jenson's inequality, we have $\mathrm{E}(\square(\mathrm{X})) \leq \square \square(\mathrm{E}(\mathrm{X}))$ when $\square(\mathrm{x})$ is a concave function and $\mathrm{X}$ is an integrable real-value random variable. Since $\square(x)=\sqrt{x}$ is a concave function, we have

$E\left(R_{2}\right)=E\left(\sqrt{\left.\frac{\widehat{D}}{D^{*}} \frac{\hat{S}}{S^{*}} \frac{\widehat{H}}{H^{*}}\right)} \leq \sqrt{E\left(\frac{\widehat{D}}{D^{*}} \frac{\hat{S}}{S^{*}} \frac{\widehat{H}}{H^{*}}\right)}=\sqrt{E\left(\frac{\widehat{D}}{D^{*}}\right) E\left(\frac{\hat{S}}{S^{*}}\right) E\left(\frac{\widehat{H}}{H^{*}}\right)}=1\right.$

when the annual demand, $\widehat{D}$, set-up cost, $\widehat{S}$, and holding cost, $\widehat{H}$, are independent and have a mean of $D^{*}, S^{*}$ and $H^{*}$, respectively. That is, on the average, the realization of the total inventory cost will be smaller than the true total inventory cost.

When $\widehat{D}, \widehat{S}$, and $\widehat{H}$ follow uniform probability distributions with a mean of $\mathrm{D}^{*}, \mathrm{~S}^{*}$, and $\mathrm{H}^{*}$, respectively, we can find out the corresponding probability distribution for the product of $\frac{\widehat{D}}{\mathrm{D}^{*}} \frac{\widehat{S}}{\mathrm{~S}^{*}} \frac{\widehat{H}}{\mathrm{H}^{*}}$ (Anderson and Doran, 1978; Hogg and Craig, 2004; and Ishihara, 2002). Accordingly, we can also find out the exact probability distribution for $\sqrt{\frac{\widehat{D}}{D^{*}} \frac{\hat{S}}{S^{*}} \frac{\widehat{H}}{H^{*}}}$. However, since finding the exact probability distribution for $\sqrt{\frac{\widehat{D}}{D^{*}} \frac{\hat{S}}{S^{*}} \frac{\widehat{H}}{H^{*}}}$ is tedious, it will not be the main focus of this study. For an illustration of the robustness of the basic EOQ, simulation outcomes for $\widehat{D}, \widehat{S}$, and $\widehat{H}$ (with a mean of $\mathrm{D}^{*}, \mathrm{~S}^{*}$, and $\mathrm{H}^{*}$, respectively) from various uniform and normal probability distributions are shown in the next section. It shows that the estimation errors for annual demand, set-up cost, and holding cost, in reality, will not cause significant impact on the total inventory costs.

\section{SIMULATION RESULTS}

Assume that ratios $\mathrm{D} / \mathrm{D}^{*}, \mathrm{~S} / \mathrm{S}^{*}$, and $\mathrm{H} / \mathrm{H}^{*}$ follow uniform probability distributions with corresponding upper and lower limits to be $10 \%, 20 \%$, and $30 \%$ from the mean of 1 .

Ten thousand random observations of each of the random rations, $\mathrm{D} / \mathrm{D}^{*}, \mathrm{~S} / \mathrm{S}^{*}$, and $\mathrm{H} / \mathrm{H}^{*}$, are generated from EXCEL. $\mathrm{R}_{2}$ ratios in Equation (4) are then obtained. Only values in the upper matrix are displayed. It is because the probability distributions for $\mathrm{D} / \mathrm{D}^{*}, \mathrm{~S} / \mathrm{S}^{*}$, and $\mathrm{H} / \mathrm{H}^{*}$ are exchangeable. That is, when $\mathrm{D} / \mathrm{D}^{*}, \mathrm{~S} / \mathrm{S}^{*}, \mathrm{H} / \mathrm{H}^{*}$ follow the distributions, $\mathrm{U}[0.9,1.1], \mathrm{U}[0.8,1.2]$, and $\mathrm{U}[0.7,1.3]$, respectively, $\mathrm{R}_{2}$ will have the same resulting probability distribution as when they follow the distributions, $\mathrm{U}[0.9,1.1]$, $\mathrm{U}[0.7,1.3]$, and $\mathrm{U}[0.8,1.2]$, respectively.

It is not difficult to find out the possible maximum and minimum values for $\mathrm{R}_{2}$ ratio. For instance, if annual demand $\mathrm{D}$, set-up cost $\mathrm{S}$, and holding cost $\mathrm{H}$ all have $30 \%$ estimation errors, the maximum and minimum values for $\mathrm{R}_{2}$ can be found by taking the square root of $1.3 * 1.3 * 1.3$ and $0.7 * 0.7 * 0.7$, which are 1.48 and 0.59 , respectively. It means with $30 \%$ errors on estimating annual demand, set-up cost and holding cost, there will be a maximum of $48 \%$ in the estimation of the total cost.

Instead of listing the possible maximum and minimum estimation errors for the total cost, the $10^{\text {th }}$ percentile and $90^{\text {th }}$ percentile are listed in Table 1. It can be seen that at the worst scenario when annual demand D, set-up cost $\mathrm{S}$, and holding cost $\mathrm{H}$ all have $30 \%$ over estimation errors, $90 \%$ of the estimate total cost realization $\widehat{\mathrm{TC}}(\widehat{\mathrm{Q}})$ will not be over the true $\mathrm{TC}^{*}\left(\mathrm{Q}^{*}\right)$ by $19 \%$. On the other hand, if at the worst scenario, when annual demand $\mathrm{D}$, set-up cost $\mathrm{S}$, and holding cost $\mathrm{H}$ all were underestimated by $30 \%, 90 \%$ of the estimate total cost realization $\widehat{\mathrm{TC}}(\widehat{\mathrm{Q}})$ will not be under the true $\mathrm{TC}^{*}\left(\mathrm{Q}^{*}\right)$ by $18 \%$. The probability distribution for $\mathrm{R}_{2}$ is quite symmetric, but slightly skewed to the right. In most cases, the total realization cost to the true unknown cost is in the neighborhood of $10 \%$. It indicates the robustness of the basic EOQ when costs follow uniform distributions. 
Table 1:

Some Descriptive Statistics for $\mathbf{R}_{2}$ When $\mathrm{D} / \mathrm{D}^{*}, \mathrm{~S} / \mathrm{S}^{*}$, and $\mathrm{H} / \mathrm{H}^{*}$ follow Various Uniform Probability Distributions

\begin{tabular}{|c|c|c|c|c|c|}
\hline & \multirow{2}{*}{$\begin{array}{l}\mathrm{D} / \mathrm{D}^{*} \\
\mathrm{U}[0.9,1.1]\end{array}$} & \multicolumn{4}{|c|}{ H/H* } \\
\hline & & & $\mathrm{U}[0.9,1.1]$ & $\mathrm{U}[0.8,1.2]$ & $\mathrm{U}[0.7,1.3]$ \\
\hline \multirow{15}{*}{$\mathrm{S} / \mathrm{S}^{*}$} & \multirow{5}{*}{$\mathrm{U}[0.9,1.1]$} & $10^{\text {th }}$ Percentile & 0.93 & 0.91 & 0.86 \\
\hline & & $90^{\text {th }}$ Percentile & 1.06 & 1.09 & 1.12 \\
\hline & & Q1 & 0.96 & 0.95 & 0.90 \\
\hline & & Median & 1.00 & 1.00 & 1.00 \\
\hline & & Q3 & 1.03 & 1.05 & 1.07 \\
\hline & \multirow{5}{*}{$\mathrm{U}[0.8,1.2]$} & $10^{\text {th }}$ Percentile & ----- & 0.88 & 0.86 \\
\hline & & $90^{\text {th }}$ Percentile & ----- & 1.10 & 1.13 \\
\hline & & Q1 & ----- & 0.93 & 0.92 \\
\hline & & Median & ----- & 0.99 & 0.99 \\
\hline & & Q3 & $\begin{array}{l}---- \\
\end{array}$ & 1.05 & 1.06 \\
\hline & \multirow{5}{*}{$\mathrm{U}[0.7,1.3]$} & $10^{\text {th }}$ Percentile & ----- & $\begin{array}{l}---- \\
-\cdots\end{array}$ & 0.83 \\
\hline & & $90^{\text {th }}$ Percentile & ----- & ----- & 1.17 \\
\hline & & Q1 & ----- & ----- & 0.90 \\
\hline & & Median & $\begin{array}{l}---- \\
\end{array}$ & $\begin{array}{l}---- \\
\end{array}$ & 0.98 \\
\hline & & Q3 & ----- & ----- & 1.07 \\
\hline \multirow{2}{*}{\multicolumn{2}{|c|}{$\begin{array}{l}\mathrm{D} / \mathrm{D}^{*} \\
\mathrm{U}[0.8,1.2]\end{array}$}} & \multicolumn{4}{|c|}{$\mathrm{H} / \mathrm{H}^{*}$} \\
\hline & & & $\mathrm{U}[0.9,1.1]$ & $\mathrm{U}[0.8,1.2]$ & $\mathrm{U}[0.7,1.3]$ \\
\hline \multirow{10}{*}{$\mathrm{S} / \mathrm{S}^{*}$} & \multirow{5}{*}{$\mathrm{U}[0.8,1.2]$} & $10^{\text {th }}$ Percentile & ----- & 0.86 & 0.83 \\
\hline & & $90^{\text {th }}$ Percentile & ----- & 1.13 & 1.16 \\
\hline & & Q1 & ----- & 0.92 & 0.91 \\
\hline & & Median & ----- & 0.99 & 0.99 \\
\hline & & Q3 & ----- & 1.06 & 1.08 \\
\hline & \multirow{5}{*}{$\mathrm{U}[0.7,1.3]$} & Minimum & ----- & ----- & 0.82 \\
\hline & & Maximum & ----- & $-\cdots$ & 1.17 \\
\hline & & Q1 & ----- & ----- & 0.89 \\
\hline & & Median & ----- & $-\cdots-$ & 0.98 \\
\hline & & Q3 & ----- & ---- & 1.09 \\
\hline \multirow{2}{*}{\multicolumn{2}{|c|}{$\begin{array}{l}\mathrm{D} \\
\mathrm{U}[0.7,1.3]\end{array}$}} & \multicolumn{4}{|c|}{$\mathrm{H}$} \\
\hline & & & $\mathrm{U}[0.9,1.1]$ & $\mathrm{U}[0.8,1.2]$ & $\mathrm{U}[0.7,1.3]$ \\
\hline \multirow{5}{*}{$\mathrm{S}$} & \multirow{5}{*}{$\mathrm{U}[0.7,1.3]$} & $10^{\text {th }}$ Percentile & ---- & ---- & 0.82 \\
\hline & & $90^{\text {th }}$ Percentile & ----- & ----- & 1.19 \\
\hline & & Q1 & ----- & $\begin{array}{l}---- \\
\end{array}$ & 0.88 \\
\hline & & Median & ----- & ----- & 0.98 \\
\hline & & Q3 & ----- & ----- & 1.09 \\
\hline
\end{tabular}

Similar results when $\mathrm{D} / \mathrm{D} *, \mathrm{~S} / \mathrm{S}^{*}$, and $\mathrm{H} / \mathrm{H}^{*}$ follow normal distributions with a mean of 1 and a standard deviation of $0.1,0.15$, and 0.2 , respectively, are shown in Table 2 . When annual demand $\mathrm{D}$, set-up cost $\mathrm{S}$, and holding cost $\mathrm{H}$ all have $20 \%$ over estimation errors, $90 \%$ of the estimate total cost realization $\widehat{\mathrm{TC}}(\widehat{\mathrm{Q}})$ will not be over the true $\mathrm{TC}^{*}\left(\mathrm{Q}^{*}\right)$ by $19 \%$. 
Table 2: Some Descriptive Statistics for $\mathbf{R}_{2}$ When $D / D^{*}, S / S^{*}$, and H/H* follow Various Normal Probability Distributions

\begin{tabular}{|c|c|c|c|c|c|}
\hline \multirow{2}{*}{\multicolumn{2}{|c|}{$\begin{array}{l}\mathrm{D} / \mathrm{D}^{*} \\
\mathrm{~N}[1,0.1]\end{array}$}} & \multicolumn{4}{|c|}{ H/H* } \\
\hline & & & $\mathrm{N}[1,0.1]$ & $\mathrm{N}[1,0.15]$ & $\mathrm{N}[1,0.2]$ \\
\hline \multirow{15}{*}{$\mathrm{S} / \mathrm{S}^{*}$} & \multirow{5}{*}{$\mathrm{N}[1,0.1]$} & $10^{\text {th }}$ Percentile & 0.89 & 0.87 & 0.85 \\
\hline & & $90^{\text {th }}$ Percentile & 1.11 & 1.13 & 1.15 \\
\hline & & Q1 & 0.94 & 0.92 & 0.91 \\
\hline & & Median & 0.99 & 0.99 & 1.00 \\
\hline & & Q3 & 1.05 & 1.06 & 1.08 \\
\hline & \multirow{5}{*}{$\mathrm{N}[1,0.15]$} & $10^{\text {th }}$ Percentile & ----- & 0.84 & 0.82 \\
\hline & & $90^{\text {th }}$ Percentile & $\begin{array}{ll}---- \\
\end{array}$ & 1.15 & 1.17 \\
\hline & & Q1 & ----- & 0.91 & 0.91 \\
\hline & & Median & ----- & 0.99 & 0.99 \\
\hline & & Q3 & ----- & 1.07 & 1.09 \\
\hline & \multirow{5}{*}{$\mathrm{N}[1,0.2]$} & $10^{\text {th }}$ Percentile & ----- & ----- & 0.78 \\
\hline & & $90^{\text {th }}$ Percentile & ----- & $\begin{array}{l}---- \\
\end{array}$ & 1.19 \\
\hline & & Q1 & ----- & $-\cdots$ & 0.88 \\
\hline & & Median & ----- & ----- & 0.99 \\
\hline & & Q3 & ----- & ----- & 1.08 \\
\hline \multirow{2}{*}{\multicolumn{2}{|c|}{$\begin{array}{l}\mathrm{D} / \mathrm{D}^{*} \\
\mathrm{~N}[1,0.15]\end{array}$}} & \multicolumn{4}{|c|}{$\mathrm{H} / \mathrm{H}^{*}$} \\
\hline & & & $\mathrm{N}[1,0.1]$ & $\mathrm{N}[1,0.15]$ & $\mathrm{N}[1,0.2]$ \\
\hline \multirow{10}{*}{$\mathrm{S} / \mathrm{S}^{*}$} & \multirow{5}{*}{$\mathrm{N}[1,0.15]$} & $10^{\text {th }}$ Percentile & ----- & 0.82 & 0.80 \\
\hline & & $90^{\text {th }}$ Percentile & ----- & 1.16 & 1.19 \\
\hline & & Q1 & ----- & 0.90 & 0.88 \\
\hline & & Median & ----- & 0.99 & 0.98 \\
\hline & & Q3 & ----- & 1.08 & 1.08 \\
\hline & \multirow{5}{*}{$\mathrm{N}[1,0.2]$} & Minimum & ----- & ---- & 0.78 \\
\hline & & Maximum & ----- & ----- & 1.19 \\
\hline & & Q1 & $\begin{array}{l}---- \\
\end{array}$ & ----- & 0.87 \\
\hline & & Median & ----- & ----- & 0.98 \\
\hline & & Q3 & ----- & ----- & 1.09 \\
\hline \multirow{2}{*}{\multicolumn{2}{|c|}{$\begin{array}{l}\mathrm{D} \\
\mathrm{N}[1,0.2]\end{array}$}} & \multicolumn{4}{|c|}{$\mathrm{H}$} \\
\hline & & & $\mathrm{N}[1,0.1]$ & $\mathrm{N}[1,0.15]$ & $\mathrm{N}[1,0.2]$ \\
\hline \multirow{5}{*}{ S } & \multirow{5}{*}{$\mathrm{N}[1,0.2]$} & $10^{\text {th }}$ Percentile & ----- & ----- & 0.76 \\
\hline & & $90^{\text {th }}$ Percentile & ----- & ----- & 1.21 \\
\hline & & Q1 & ----- & ----- & 0.86 \\
\hline & & Median & ----- & ----- & 0.98 \\
\hline & & Q3 & $\begin{array}{ll}---- \\
\end{array}$ & ----- & 1.09 \\
\hline
\end{tabular}

\section{CONCLUSION}

In this study, annual demand, set-up cost, and holding cost are assumed to be random variables with an unknown means at $\mathrm{D}^{*}, \mathrm{~S}^{*}$, and $\mathrm{H}^{*}$, respectively, instead of treating them as unknown numbers in an interval in Low and Schwarz's paper (1983). Instead of comparing $\mathrm{TC}^{*}(\widehat{\mathrm{Q}})$ and $\mathrm{TC}^{*}\left(\mathrm{Q}^{*}\right)$, we compare $\widehat{\mathrm{TC}}(\widehat{\mathrm{Q}})$ and $\mathrm{TC}^{*}\left(\mathrm{Q}^{*}\right)$. In practice, the realization of $\widehat{\mathrm{D}}, \widehat{\mathrm{S}}$, and $\widehat{\mathrm{H}}$ will be treated as the true annual demand, set-up cost, and holding cost, and will be used to calculate the total cost $\widehat{\mathrm{TC}}(\widehat{\mathrm{Q}})$.

Simulation results show that when $\widehat{\mathrm{D}}, \widehat{\mathrm{S}}$, and $\widehat{\mathrm{H}}$ follow uniform probability distributions with a possible under or over estimate from their unknown true costs $\mathrm{D}^{*}, \mathrm{~S}^{*}$, and $\mathrm{H}^{*}$ by $20-30 \%$, simulation results show $90 \%$ of the ratios of $\widehat{\mathrm{TC}}(\widehat{\mathrm{Q}})$ to $\mathrm{TC}^{*}\left(\mathrm{Q}^{*}\right)$ will not be over $19 \%$ under this situation. It shows the robustness of the basic EOQ under common situations when annual demand, set-up, and holding costs follow various uniform and normal probability distributions. 


\section{AUTHOR INFORMATION}

Dr. Louie Ren received his Ph.D. from the Department of Information System and Quantitative Science, Texas Tech University. $\mathrm{He}$ is an Associate Professor in the Department of Accounting, Economics, Finance, and Quantitative Management Science of the University of Houston - Victoria. His research interest is in business forecasting, inventory management, and statistical quality control.

\section{REFERENCES}

1. Anderson, J. R. and H. E. Doran, "Some Properties of Simple Functions of Random Variables," Review of Marketing and Agricultural Economics, Vol. 46, No. 1, April, 1978, pp. 37-47.

2. Craig, A, J. W. McKean, and R. V. Hogg, Introduction to Mathematical Statistics, $6^{\text {th }}$ edition, Prentice Hall, 2004.

3. Dobson, G., "Sensitivity of the EOW Model to Parameter Estimate," Operations Research, Vol. 36, No. 4, July-August, 1988, pp. 570-574.

4. Ishihara, T., "The Distribution of the Sum and the Product of Independent Uniform Random Variables Distributed at Different Intervals," (in Japanese), The Japan Society for Industrial and Applied Mathematics, Vol. 12, No. 3, 2002, pp. 197-207.

5. Lowe, T. J. and L. B. Schwarz, "Parameter Estimation for the EOQ Lot-Size Model: Minimax and Expected Value Choices," Naval research Logistics Quarterly, vol. 30, 1983, pp. 367-376.

6. Stevenson, W. J., Operations Management, $10^{\text {th }}$ edition, McGraw-Hill, 2009. 